\title{
DETACHED SUPERIOR RECTUS FOLLOWING SCLERAL BUCKLING: ANATOMY AND SURGICAL MANAGEMENT
}

\author{
J. D. A. MACLEOD and R. J. MORRIS \\ Southampton
}

\begin{abstract}
SUMMARY
We describe two patients who developed vertical diplopia following circumferential scleral buckling for retinal detachments. Both were found to have hypodeviation and impaired elevation of the operated eye. In each case this was initially ascribed to the presence of the buckle itself, but there was no clinical improvement when this was subsequently removed, and the insertion of the superior rectus was therefore explored. In both patients this muscle was found to be detached from its normal insertion, and was identified in a retracted position overlying the insertion of the superior oblique. Following surgical re-attachment of the superior rectus, ocular elevation was restored, with resolution of symptoms.
\end{abstract}

Ocular motility abnormalities are frequent after scleral buckling surgery. ${ }^{1-4}$ In a prospective study, Smiddy et $_{\mathrm{al}}{ }^{3}$ found persistent limitation of ductions in $73 \%$ of cases, and heterotropia in the primary position in $23 \%$. They suggested that the most important mechanism was restrictive fibrosis. In this

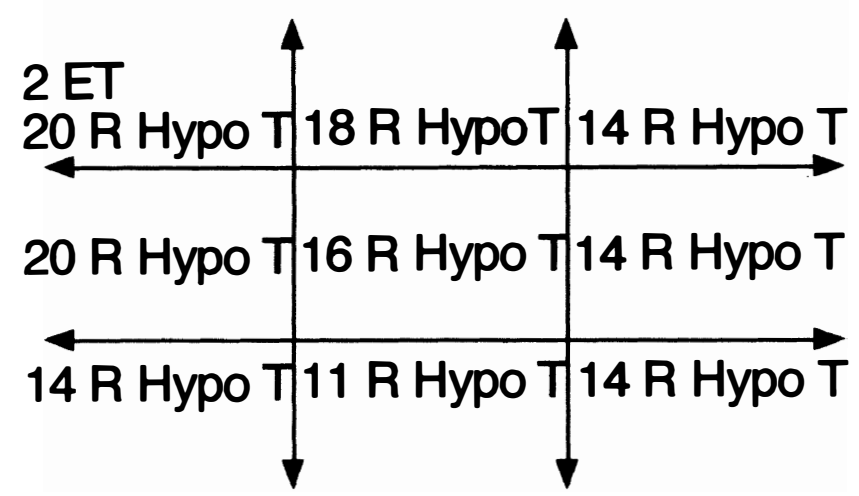

Fig. 1. Case 1. Prism cover test measurements in different positions of gaze (prism dioptres) before strabismus surgery. ET, esotropia; Hypo T, hypotropia.

Correspondence to: Mr R. J. Morris, Southampton Eye Unit, Southampton General Hospital, Tremona Road, Southampton SO16 6YD, UK. report we discuss the diagnosis and management of two patients whose diplopia was caused by an alternative mechanism: disinsertion of a rectus muscle.

\section{Case 1}

\section{CASE REPORTS}

A 59-year-old man with a right superior retinal detachment was successfully treated with vitrectomy,

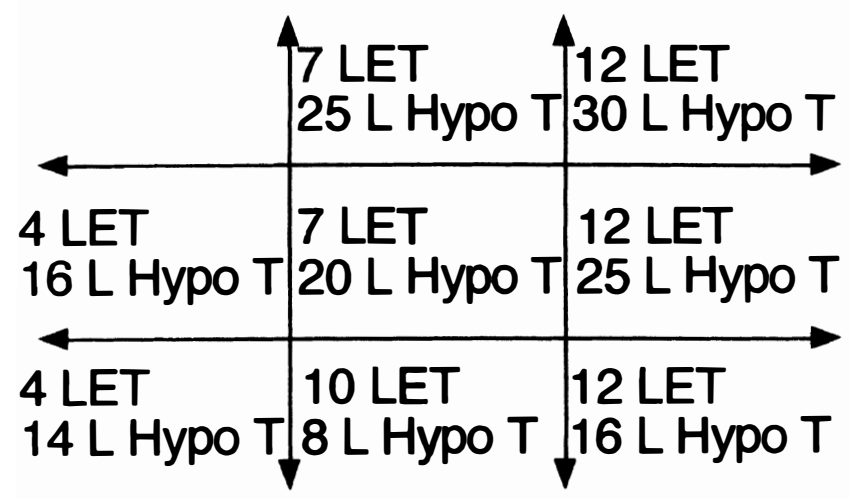

(a)

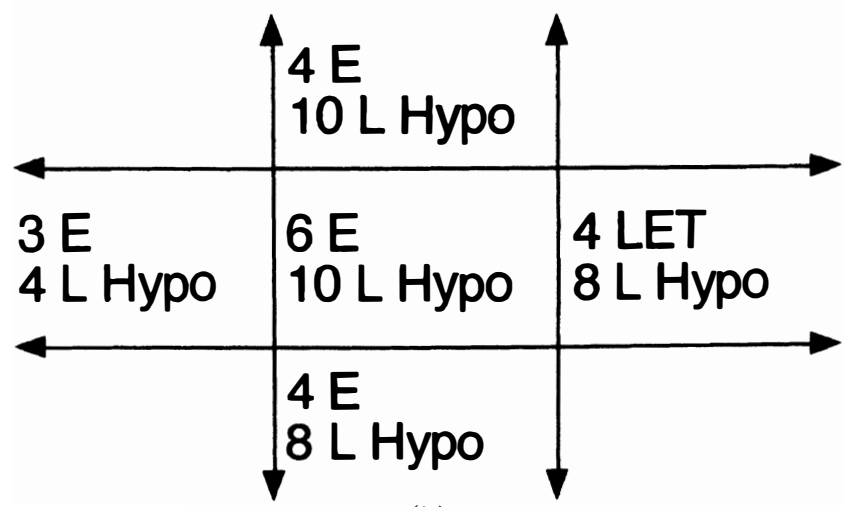

(b)

Fig. 2. Case 2. Prism cover test measurements in different positions of gaze (prism dioptres): (a) before and (b) 4 months after strabismus surgery. ET, esotropia; E, esophoria; Hypo T, hypotropia; Hypo, hypophoria.

Eye (1997) 11, 30-32 (C) 1997 Royal College of Ophthalmologists 
FIELD OF LEFT EYE (fixing with right eye)

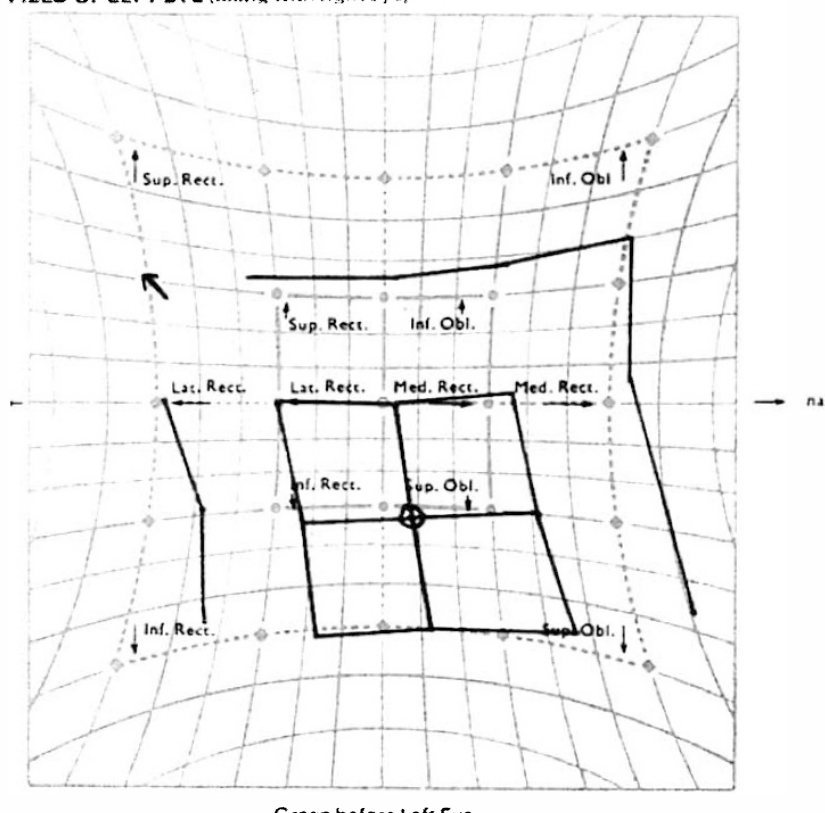

Green before Left Eye

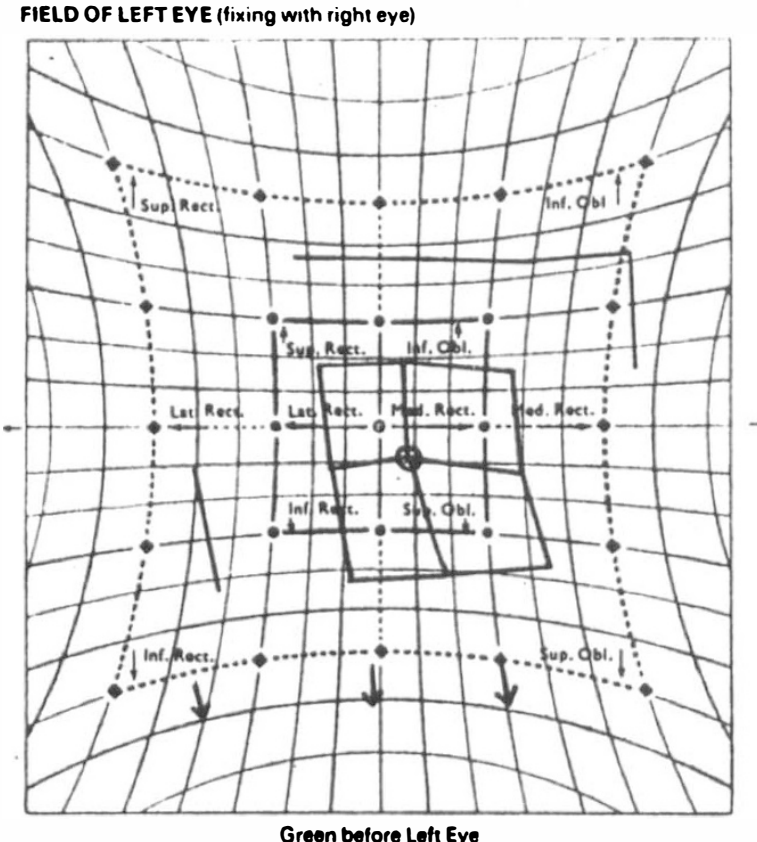

FIELD OF RIGHT EYE (fixing with left eye)

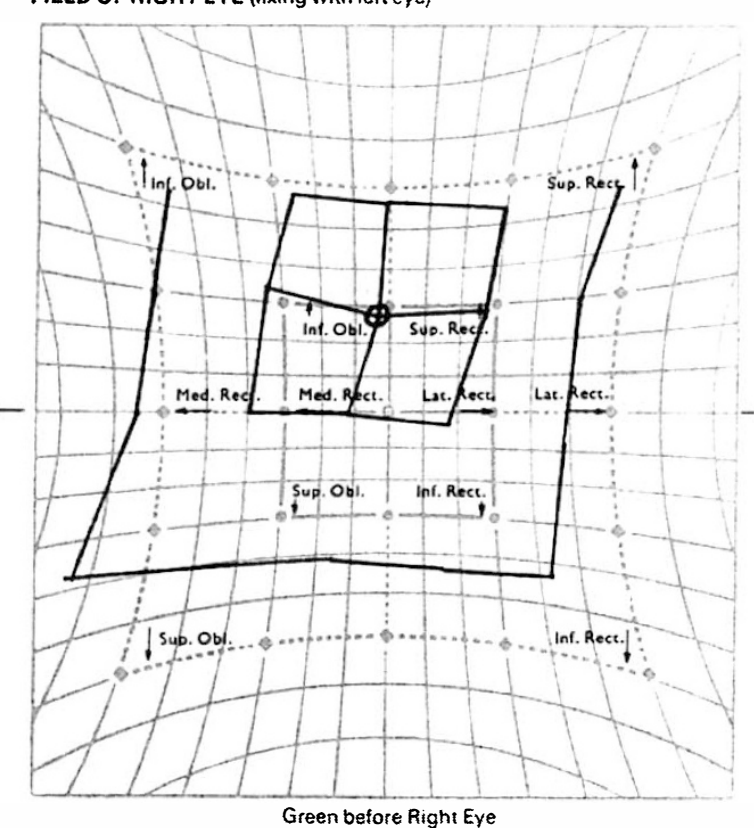

(a)

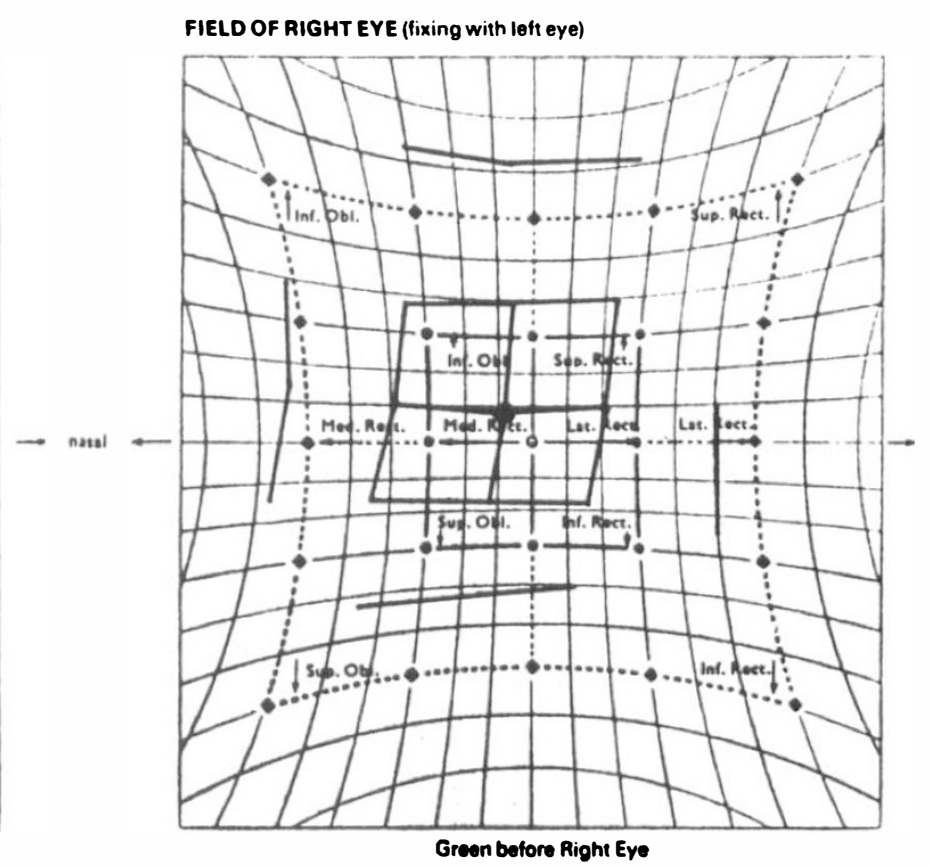

(b)

Fig. 3. Case 2. Hess chart results: (a) before and (b) 4 months after strabismus surgery.

endolaser and a circumferential silicone 279 buckle running behind the medial, lateral and superior recti. Two months after surgery he became aware of vertical diplopia, which was ascribed to the presence of the buckle, and was treated with a Fresnel prism. Four months after surgery the silicone buckle began to extrude superiorly, but its removal did not improve the diplopia.

The patient was assessed in the ocular motility clinic 5 months after the retinal surgery. At that time acuities were $6 / 9$ right and $6 / 5$ left, and prism cover test results were as shown in Fig. 1.

Surgical exploration of the superior rectus insertion site failed to reveal the muscle, which was finally identified, amidst considerable scar tissue, in a retracted position attached to the insertion of the superior oblique tendon, and to the sclera immediately behind this tendon. These muscles were carefully separated, and the superior rectus was readvanced on adjustable sutures to a point $4.5 \mathrm{~mm}$ 


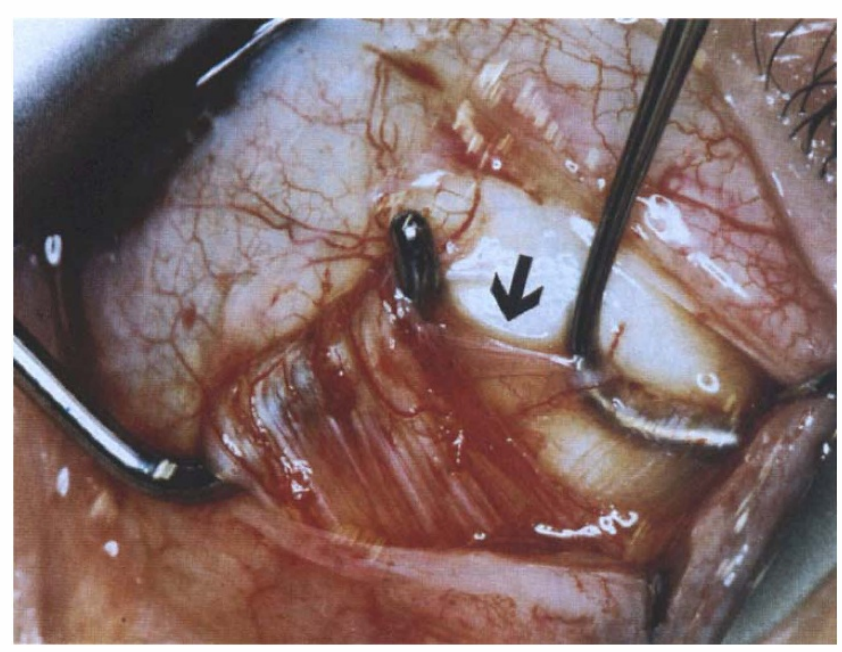

Fig. 4. Normal anatomy in a right eye: the band of Tenon's capsule is shown (arrow) which links the superior rectus muscle (on the large squint hook) to the superior oblique muscle (on the small squint hook). The limbus is at the top left of the picture.

behind the original insertion. Post-operatively no adjustment was required, and no further diplopia was experienced by this patient. At his final review 7 months later, prism cover testing in all positions of gaze revealed no heterotropia.

\section{Case 2}

A 71-year-old man developed a left retinal detachment, which was successfully treated with an encircling silicone band and a superotemporal circumferential buckle. This surgery was followed by persisting vertical diplopia which did not improve after removing the eroding strap and buckle 4 years later.

The patient was referred to the motility clinic. Visual acuities were 6/6 right and 6/60 left, with prism cover tests as shown in Fig. 2a. At surgery, the left superior rectus was found $12 \mathrm{~mm}$ from the limbus, attached to the insertion of the superior oblique tendon. After careful separation of the muscles, the superior rectus was reattached $7 \mathrm{~mm}$ back from the limbus.

Post-operatively he has remained virtually asymptomatic, developing diplopia only when tired. At his most recent review, 4 months after surgery, prism cover testing in all positions of gaze revealed a small left hypophoria and esophoria but no diplopia, with stereopsis of $200^{\prime \prime}$ of arc on Titmus testing (Fig. 2b). The improvement in Hess chart measurements is shown in Fig. 3.

\section{DISCUSSION}

Migration of silicone explants through rectus muscle insertions is a rare complication of scleral buckling surgery, and does not necessarily result in a motility disorder, as the muscle may develop new scleral attachments behind the migrating explant. ${ }^{5-7}$ Both slim encircling bands such as MIRA 240, and wider local buckles such as MIRA 279, have been involved. ${ }^{5,6}$ It is not clear how soon after retinal surgery this may occur, as it is possible that fibrosis may cause symptoms of diplopia before the insertion is severed. However, our case 1 indicates that disinsertion may occur within 4 months of retinal surgery. Disinsertion of a rectus muscle should be strongly suspected when extrusion of an explant through the conjunctiva in front of a muscle insertion is combined with underaction of that muscle.

In each of our cases we were able to find the superior rectus by first identifying the insertion of the superior oblique. This can be explained by the band of Tenon's capsule which normally joins the two muscles at this point, and appears to prevent further retraction of a disinserted superior rectus (Fig. 4). ${ }^{8,9}$

Silicone scleral explants can erode through rectus muscle insertions, sometimes causing distressing diplopia. In the case of the disinserted superior rectus, knowledge of its normal attachment to the superior oblique enables the surgeon to restore normal anatomy and function.

Key words: Scleral explants, Superior rectus muscle.

\section{REFERENCES}

1. Waddell E. Retinal detachment and orthoptics. $\mathrm{Br}$ Orthopt J 1983;40:5-12.

2. Mets MB, Wendell ME, Gieser RG. Ocular deviation after retinal detachment surgery. Am J Ophthalmol 1985;99:667-72.

3. Smiddy WE, Loupe D, Michels RG, Enger C, Glaser BM, Debustros S. Extraocular muscle imbalance after scleral buckling surgery. Ophthalmology 1989;96: 1485-90.

4. Spencer AF, Newton C, Vernon SA. Incidence of ocular motility problems following scleral buckling surgery. Eye 1993;7:751-6.

5. Ashkenazi I, Moisseiev J, Bartov E, Treister G. Preserved action of a rectus muscle after transection by an encircling solid silicone band. $\mathrm{Br} \mathrm{J}$ Ophthalmol 1991;75:508-9.

6. Lanigan LP, Wilson-Holt N, Gregor ZJ. Migrating scleral explants. Eye 1992;6:317-21.

7. Maguire AM, Zarbin MA, Eliott D. Migration of solid silicone encircling element through four rectus muscles. Ophthalmic Surg 1993;24:604-7.

8. Fink WH. Surgery of the oblique muscles of the eye, 1st ed. St Louis: CV Mosby, 1951.

9. Plager DA, Parks MM. Recognition and repair of the 'lost' rectus muscle: a report of 25 cases. Ophthalmology 1990;97:131-7. 